\title{
Testing dose-dependent effects of stacked Bt maize pollen on in vitro-reared honey bee larvae
}

\author{
Karin SteiJven, Ingolf StefFan-Dewenter, Stephan HÄrtel \\ Department of Animal Ecology and Tropical Biology, Biocenter, University of Würzburg, Am Hubland, 97074, \\ Würzburg, Germany
}

Received 20 February 2015 - Revised 17 July 2015 - Accepted 10 September 2015

\begin{abstract}
In agricultural landscapes all over the world, honey bees are exposed to genetically modified (GM) pollen. Stacked Bt-maize varieties combine multiple Bt proteins against different insect taxa with herbicide resistance. To test for potential effects on non-target organisms, we conducted an in vitro larvae-rearing experiment where we fed increasing amounts of stacked Bt pollen to honey bee larvae. Bt pollen was equally well digested as two control maize varieties. No dose-dependent effects of Bt maize were detected in terms of survival and developmental delay. However, for prepupal weight we did find a dose-dependent response, suggesting a pleiotropic effect. Comparing this finding with the literature we conclude that the found effect is not likely to occur in a field situation. We could however show that dose-dependent effects are detectable. Our results underline the importance of testing dose-depending effects of GM plant material in an environmental risk assessment (ERA).
\end{abstract}

\section{environmental risk assessment / transgenic pollen / Apis mellifera / ecotoxicology / sub-lethal effects}

\section{INTRODUCTION}

Currently, one of the most common and most widely grown genetically modified organisms (GMOs) are Bt crops. Bt stands for Bacillus thuringiensis, a bacterium which expresses proteins toxic to specific insects depending on the strain (Schnepf et al. 1998). The mode of action of this protein is that it binds to a receptor in the insect's gut, after which it starts to form pores in the gut (Schnepf et al. 1998). A development in the commercial cultivation of Bt crops is the accumulation of multiple transgenes within a so called 'stacked' plant. Peer-reviewed ERA studies for this kind of Bt crops are still rarely available

Electronic supplementary material The online version of this article (doi:10.1007/s13592-015-0392-8) contains supplementary material, which is available to authorized users.

Corresponding author: K. Steijven, karin.steijven@uniwuerzburg.de

Handling Editor: Monique Gauthier
(Hendriksma et al. 2011a, b, 2012; Schuppener et al. 2012; Niu et al. 2013; Whitehouse et al. 2014). Worldwide cropping area of transgenic crops covers 1.6 billion hectares, of which 57.4 million hectares is transgenic maize (James 2013). Since honey bees occur globally, they cooccur with many GMOs. Even though maize is a wind-pollinated plant, it has been shown that honey bees frequently forage for pollen on maize flowers (Danner et al. 2014). Pollen is the sole protein source for honey bees and it is essential for the growth of the larvae. Nurse bees are the "turntable" for proteins within the colony, they ingest pollen and feed the larvae with protein-rich jelly (Crailsheim 1990; Crailsheim et al. 1992). The larvae receive the main part of proteins via this glandular secretion, but a minor part of proteins is also provided in form of pollen grains (Haydak 1943; Babendreier et al. 2004). Since Bt protein $(\mathrm{Cry} 1 \mathrm{Ab})$ is not secreted via nurse bee feeding glands to the brood (Babendreier et al. 2005), larvae are only exposed to transgenic insecticidal proteins via direct consumption of transgenic plant 
material, i.e., Bt pollen. As the honey bee is a very important pollinator in many agroecosystems, it is of the utmost importance that the possible effects of GMOs on honey bees and honey bee health are thoroughly studied. Since Bt crops are targeted against the larval stages of the pest insects, and the larval phase is likely to be the most sensitive phase (Romeis et al. 2011), it is important to do controlled studies of their effects on the larvae of honey bees. It has been pointed out that the direct exposure to plant-produced $\mathrm{Bt}$ protein must be part of environmental safety studies of GMOs (Andow and Hilbeck 2004; Duan et al. 2010); therefore, we chose to feed Bt pollen directly. We followed the principle that the poison is the dose (Paracelsus), not the substance in itself. This principle is well implemented in ecotoxicological testing of agro-chemicals, whereas in testing GM plant material, the application of this principle is not yet standard practice. Thus, we tested the direct effect of increasing doses of $\mathrm{Bt}$ pollen on the development of honey bees used in an in vitro larvae-rearing method. In addition to mortality rate and prepupal weight, we included two novel sub-lethal assessment endpoints. We quantified pollen digestion to see if honey bee larvae are able to digest the stacked $\mathrm{Bt}$ pollen, and thus quantifying the exposure to the transgenic proteins therein. And we recorded developmental stage at the end of the experiment as a measure for developmental delay.

\section{MATERIALS AND METHODS}

\subsection{In vitro larvae rearing}

We conducted an in vitro larvae-rearing experiment with honey bee larvae from 11 different colonies (own apiary, University of Würzburg, Germany) with unrelated queens that were mated on site. For the first two trials (19 and 30 July 2012), we obtained first instar larvae using an artificial comb system (Cupularva queen rearing system by Nicotplast (C), Maisod, France) inside the hives, according to the method described by Hendriksma et al. (2011a). Larvae were moved to the lab on the first day after hatching, placed in sterile 48-well plates and kept in a desiccator within a brood stove $\left(35^{\circ} \mathrm{C}\right.$ and $\left.95 \% \mathrm{RH}\right)$. Larvae from different colonies were distributed haphazardly over the well plates. Later on in the season, $(10,11$, and 25 September 2012), honey bee larvae were collected via grafting (Aupinel et al. 2005, 2009). Usually, young larvae do not directly receive pollen in their food (Malone et al. 2002), thus we started our experimental pollen treatments with third instar (L3) larvae (Hendriksma et al. 2011b). We reared a total 1,002 larvae that were divided more or less equally over the treatment groups, Table I-S in the Online Ressource shows exactly how larvae were distributed. Larvae were fed according to a modified version of the feeding protocol of Aupinel et al (2005, 2009); diet C was fed instead of diet B on day 6 (D6) of the development cycle. The artificial diets consisted out of $50 \%$ royal jelly and $50 \%$ sugar solution $(w / w)$. The sugar solutions in diets A and C contained $24 \%$ sugar with $2 \%$ yeast extract, and $36 \%$ sugar with $4 \%$ yeast extract $(w / w)$, respectively. On the first day of feeding, D4, larvae received $20 \mu \mathrm{L}$ of diet A, on D5 larvae were not fed, from D6 until D9 larvae received an increasing amount of diet $\mathrm{C}(20,30,40,50 \mu \mathrm{L}$, respectively) spiked with pollen. In the literature, the amount of pollen that is directly mixed into the worker jelly by nurse bees varies, probably depending on pollen type being investigated and quantification method, ranging from 1.5 to $9.4 \mathrm{mg}$ per larva (Hanley et al. 2003; Babendreier et al. 2004; Hrassnigg and Crailsheim 2005; Keller et al. 2005). We fed our larvae 1, 2, 5, and $10 \mathrm{mg}$ of pollen directly, to test for potential dose-dependent effects. For an overview of the feeding schedule, we refer to Table II-S (Online Ressource). Mortality was recorded until pupation. Dead larvae can be easily recognized by discolorations, or when they seized to breathe. Individuals were weighed at the end of the experiment at D11. All remaining individuals were killed by freezing them at $-20^{\circ} \mathrm{C}$. Any residues that resulted from molting or defecation were carefully removed and the fresh weight of the bees was measured. Additionally, we quantified two novel, sublethal endpoints; we defined the digestion of pollen (see below) and we compared the development stages at D11. Larvae were either classified as a prepupa, or as a larva, and when they 
were still in the larval stage, the instar was estimated based on their size.

\subsection{Pollen}

Five different pollen types were fed to the larvae. The stacked Bt pollen contained the events MON89034 and MON88017 in the genetic background of the variety DKc 5143. MON89034 expresses two lepidopteranspecific insecticidal proteins (Cry1A.105 and Cry2Ab2) that provide the plant resistance against the fall armyworm (Spodoptera $s p$ ), the black cutworm (Agrotis ipsilon), the European corn borer (Ostrinia nubilalis), and Corn earworm (Helicoverpa zea). The mean expression was $4.24 \mu \mathrm{g} / \mathrm{g}(\min 1.55 \mu \mathrm{g} / \mathrm{g}$, $\max 11.67 \mu \mathrm{g} /$ $\mathrm{g}, n=16)$ and $1.19 \mu \mathrm{g} / \mathrm{g}(\min 0.24 \mu \mathrm{g} / \mathrm{g}, \max 3.74 \mu \mathrm{g} / \mathrm{g}$, $n=16$ ) fwt in pollen for Cry1A.105 and Cry2Ab2, respectively (Hendriksma et al. 2011b). The event MON88017 expresses the protein Cry3Bb1 which offers resistance to beetles (Diabrotica spp .), and a fourth transgenic protein; CP4 EPSPS, that makes the plant tolerant to glyphosate, the active ingredient of the herbicide Roundup ${ }^{\circledR}$ (Monsanto). The mean expression of Cry3Bb1 was $6.95 \mu \mathrm{g} / \mathrm{g}$ in fwt pollen ( $\min 1.11 \mu \mathrm{g} / \mathrm{g}$, $\max 13.13 \mu \mathrm{g} / \mathrm{g}$ ) and of CP4 EPSPS, the enzyme providing herbicide tolerance, $170 \mu \mathrm{g} / \mathrm{g}$ (Hendriksma et al. 2011b). Pollen from DKc5143 was used as a negative control, since DKc5143 is the near-isogenic line to the tested stacked Bt maize (DKc 5143-Bt MON89034 x MON88017). Furthermore, a third, more distant related maize variety 'Benicia' (Pioneer, HiBred, Johnston, Iowa, USA) and multifloral pollen were also fed to the larvae to provide a baseline (negative controls). The three maize pollen samples were collected from an experimental field near Braunschweig (Germany) and immediately frozen (Hendriksma et al. 2011b, 2013). Multi-floral pollen was collected using a pollen trap in front of two beehives in our apiary at Würzburg University (Germany). We used toxic Heliconia pollen as a positive control (Hendriksma et al. 2011b). Toxic pollen was collected from flowering Heliconia jacquinii plants, from the Botanical Garden of Würzburg University. Heliconia flowers are very wet and sticky, and extracting pollen from them is quite a strenuous exercise. During the flowering period, individual flowers with dehiscent anthers were collected twice a week and pollen was extracted. After sampling, all pollen samples were stored at $-80{ }^{\circ} \mathrm{C}$. The pollen types were fed in increasing doses: $0,1,2,5$, and $10 \mathrm{mg} \mathrm{larva}^{-1}$, fed additively over four consecutive days (D6-D9) providing a fresh portion of pollen every day. The supplied diet was completely consumed by the larvae.

\subsection{Dissection of larvae and digestion rate}

A subsample of three to four larvae per experimental treatment per repetition was taken at least $6 \mathrm{~h}$ after the last feeding on D9, resulting in a subset of 192 larvae. In the treatment groups fed with toxic pollen, most larvae had already died up to that point. We chose to not take a sub-sample of those larvae; instead, we followed the mortality of the larvae that remained until the end of the experiment. Previously frozen larvae were pinned on a paraffin preparation plate and a careful ventral dissection was performed. Both mid and hind gut were taken out entirely and suspended in $200 \mu \mathrm{L}$ of $0.5 \mathrm{M}$ glucose solution and stored at $-20{ }^{\circ} \mathrm{C}$. The content of each sample was gently pipetted up and down 10 times and vortexed for $30 \mathrm{~s}$ before pollen counts, to rupture the gut tissue and create a suspension with uniform distribution. A Neubauer hemocytometer with two counting chambers was used to quantify the digestion rate. For the first 50 pollen grains on a counting chamber the digestion was scored according to the remaining pollen grain in the exine; $0-10 \%$ remaining pollen grain was scored as "fully digested", $10-90 \%$ remaining pollen grain is scored as "partly digested", and more than $90 \%$ remaining pollen grain was scored as 'undigested' (also see Babendreier et al. 2004). This procedure was repeated once, thus resulting in four subsamples per larva gut (two times two counting chambers).

\subsection{Statistical analysis}

All statistical tests were performed using R statistical software (RCoreTeam 2013). At the time the subsamples were taken to determine the digestion (D9), too few of the larvae from the toxic treatment were still alive (less than four) to be taken out of the survival experiment. Digestion rate was quantified using a weighted mean of scored digestion. The number of pollen kernels in each class (i.e., fully, partly or not digested) was multiplied by the mean digestion of that class to come to a weighted percentage as a quantification of digestion rate. Weighted average digestion was then analyzed with a linear mixed effects model (package lme4; Bates et al. 2013). Survival was compared with a Cox proportional hazards mixed effects regression (package 
coxme; Therneau 2012). Prepupal weight was analyzed with a linear mixed effects model (package lme4; Bates et al. 2013). Developmental delay was analyzed using a cumulative link mixed model fitted with the Laplace approximation (package ordinal; Christensen 2013). For the endpoints prepupal weight and developmental delay that were taken at the end of the experiment (D11), we did not have any values for the two highest doses toxic pollen, 5 and $10 \mathrm{mg}$, since larvae that received those amounts had already died at that point of the experiment. Pollen type and dosage were included as fixed factors. Colony background and well plate nested within date nested within grafting method (double nesting) were included as random factors. Normality and homogeneity of residuals was checked and verified for all linear regression type models. The post hoc test of the digestion analysis was done with a Tukey test, for the prepupal weight this was done with a manually constructed contrast matrix (package multcomp, Hothorn et al. 2008). Correction for multiple comparisons was done via the Benjamini Hochberg procedure (Benjamini and Yekutieli 2001).

\section{RESULTS}

\subsection{Digestion}

There was no interaction between pollen type and dosage (ANOVA; $\chi^{2}=0.2037, d f=3, P$ val$\mathrm{ue}=0.977)$, nor was there a significant effect of dosage on the digestion (ANOVA; $\chi^{2}=0.1066$, $d f=3, P$ value $=0.744 ; n=192)$, thus the factor dosage was taken out of the final model. Bt pollen was digested as well as the other two maize pollen types. Benicia pollen was less well digested than pollen from the comparator. All maize pollen types were digested better than the multifloral pollen (Figure 1), statistics are shown in Table I. For the maize pollen types overall, we found $6.1 \%$ were fully digested pollen grains, $41.8 \%$ were partly digested and $52.1 \%$, remained undigested, resulting in an overall weighted average digestibility of $19.5 \%$.

\subsection{Survival}

We reared a total of $n=1,002$ larvae. We found a significant interaction between pollen type and dosage (LRT: $\chi^{2}=24.07, d f=4, P$ value $<0.001$, $n=1,002)$. Each pollen type was fed at $0 \mathrm{mg}$ (background mortality), 1, 2, 5, and $10 \mathrm{mg}$. Note that all groups in the 0-mg group received the same base diet, without any pollen. When fed toxic pollen (positive control), mortality was 4.08 times higher compared to the Bt pollen treatment $($ Cox proportional hazard $=4.08, z$ value $=$ $5.94, P$ value $<0.001)$. There was no difference in mortality between $\mathrm{Bt}$ maize and the negative controls (Figure 2). Only the larvae fed with toxic pollen showed a significant dose-dependent response on survival (Cox proportional hazard= $1.09, z$ value $=2.45, P$ value $=0.014$ ), i.e., per $1 \mathrm{mg}$ more toxic pollen mortality increased with factor 1.09 .

\subsection{Prepupal weight}

We found a significant interaction between pollen type and the dose fed on prepupal weights (LRT; $\chi^{2}=88.245, d f=4, P$ value $<0.001, n=$ 382 ). There was no overall effect of feeding increasing amounts of pollen, only larvae fed with $\mathrm{Bt}$ pollen and toxic pollen showed a significant dosedependent negative response in weight (Figure 3, Table II). With every 1-mg pollen, larvae became lighter by 3.5 and $47.4 \mathrm{mg}$ for Bt and toxic pollen, respectively. Larvae from the Bt treatment group decreased in weight with increasing amount of pollen fed compared to all negative controls. However, also the other maize pollen treatments showed a trend towards reduced weight with higher amount of pollen; weight of near isogenic and Benicia pollen-fed larvae was marginally negatively dose dependent. This negative trend did not occur with larvae that were fed multifloral pollen. All statistics are shown in Table II.

\subsection{Developmental delay}

The expected development stage at day 11 would be the prepupal stage; however, we found a proportion of larvae that had not yet reached the prepupal stage in all treatment groups, regardless of amount of pollen fed (Figure 4). For the group that received only the artificial diet ( $0 \mathrm{mg}$ pollen), 22.9 to $37.1 \%$ of the larvae had not yet reached the prepupal stage. There was a significant interaction between pollen type and dose fed (LRT: $\chi^{2}=$ 

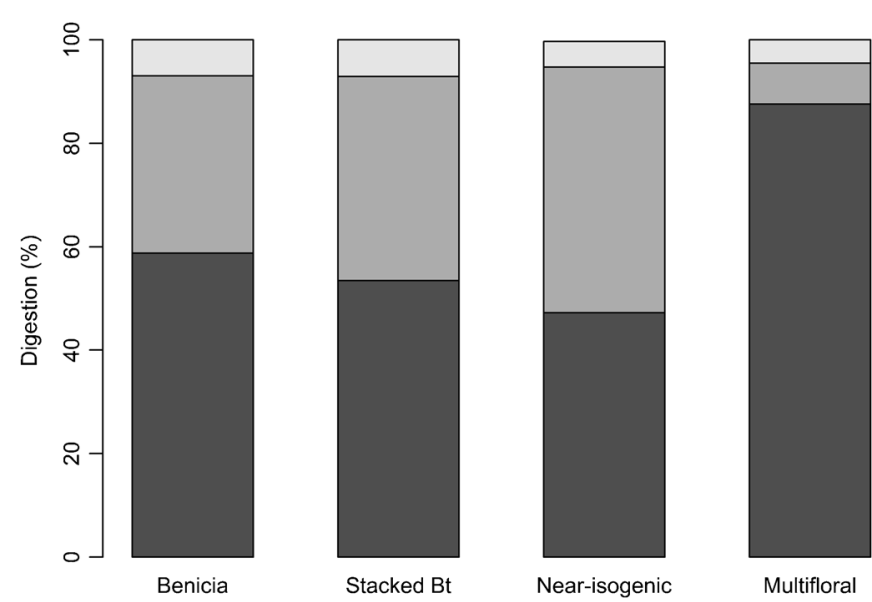

Figure 1. Digestion rate for the different types of pollen used in this experiment. Data for all dosage levels $(1,2,5$, and $10 \mathrm{mg}$ ) are pooled. Light gray represents the fully digested pollen kernels, gray the partly digested ones, black the undigested pollen kernels. Statistics are shown in Table I.

$85.495, d f=4, P$ value $<0.001, n=497)$, but only in larvae fed toxic pollen this did result in a dosedependent negative effect on the development stage (cumulative link mixed model: $z$ value $=$ $-6.474, P$ value $<0.001$ ). Bt larvae did not develop significantly slower than negative controls; there was a marginal difference between Bt-fed larvae and larvae that received near isogenic pollen (cumulative link mixed model: $z$ value $=1.798, P$ value $=0.072$ ) and no significant difference compared to Benicia pollen (cumulative link mixed model: $z$ value $=1.166, P$ value $=0.243$ ) or multifloral pollen (cumulative link mixed model: $z$ value $=-0.175, P$ value $=0.861)$. None of the larvae fed with toxic pollen reached the prepupal development stage at the end of the experiment.

\section{DISCUSSION}

Environmental risk assessment of transgenic plants needs robust test approaches that allow for biologically relevant interpretations. Depending on the surrounding agricultural landscape, bee larvae are exposed to a variety of GM crop pollen quantities in the field, but a test system analyzing different amounts of GM pollen in the diet is missing in environmental risk assessment studies. Here, we used an in vitro-rearing method to study dose-dependent effects of transgenic Bt pollen on honey bee larvae. We treated Bt pollen as if it were an insecticide and administered it in field realistic, increasing doses, as is common practice in ecotoxicological studies. In addition to the

Table I. This table compares the average weighted digestion between different pollen types that were fed by testing if the difference between two pollen types is the same as zero.

\begin{tabular}{lccccc}
\hline & Estimate & Std. error & $z$ value & $p$ value & Significance \\
\hline Bt_stacked-Benicia $=0$ & 1.9354 & 1.1121 & 1.74 & 0.0982 & \\
Comparator-Benicia=0 & 2.654 & 1.1055 & 2.401 & 0.0245 & $*$ \\
Multi floral-Benicia $=0$ & -10.2952 & 1.1436 & -9.003 & $<2 \mathrm{e}-16$ & $* * *$ \\
Comparator-Bt_stacked=0 & 0.7186 & 1.0416 & 0.69 & 0.4902 & \\
Multi floral-Bt_stacked=0 & -12.2306 & 1.1181 & -10.938 & $<2 \mathrm{e}-16$ & $* * *$ \\
Multi floral-comparator $=0$ & -12.9492 & 1.1123 & -11.641 & $<2 \mathrm{e}-16$ & $* * *$ \\
\hline
\end{tabular}

Asterisks depict level of significance: ${ }^{*} p<0.05,{ }^{* * *} p<0.001$ 


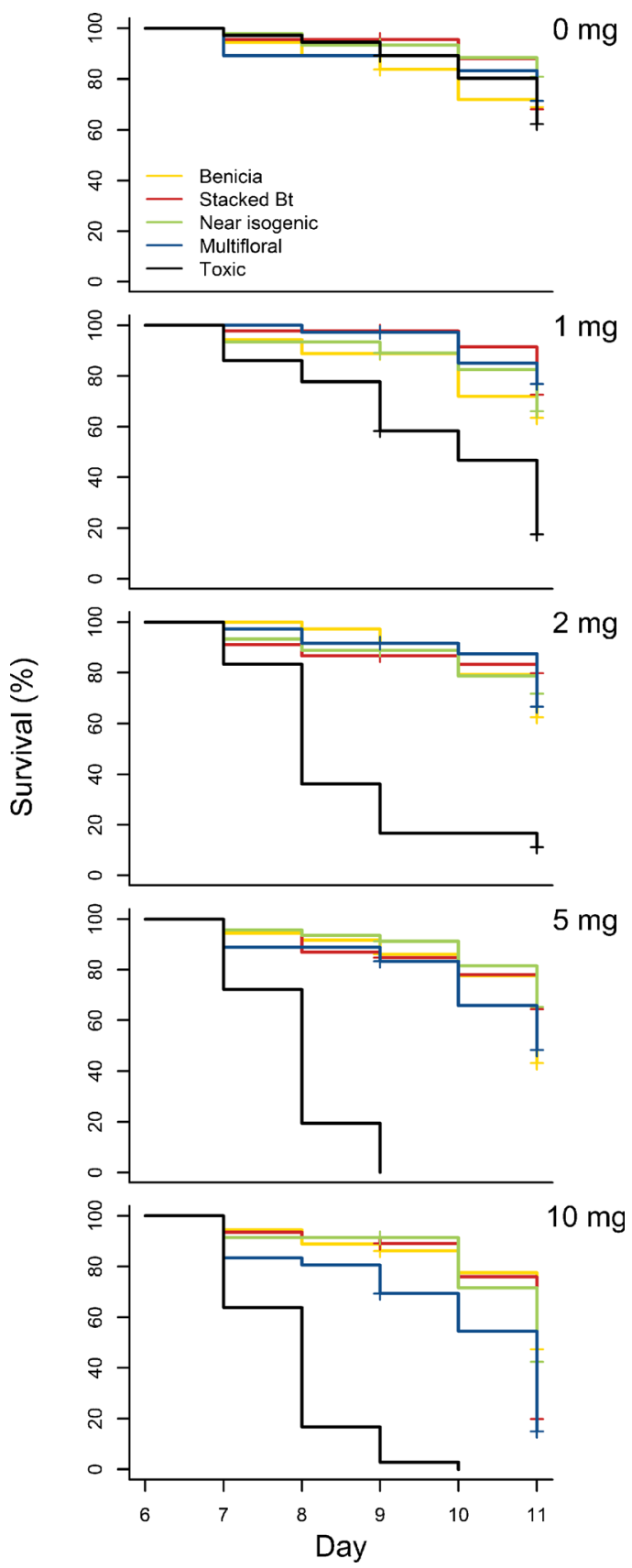

Figure 2. Survival curves for in vitro-reared honey bee larvae; $x$ axis show the development day counted from the day the eggs were laid, $y$ axis shows survival in percentage. Pollen treatments were administered from day six until day 9, the last day of feeding. Mortality was recorded for two more days, until day 11. Statistical values are in text.

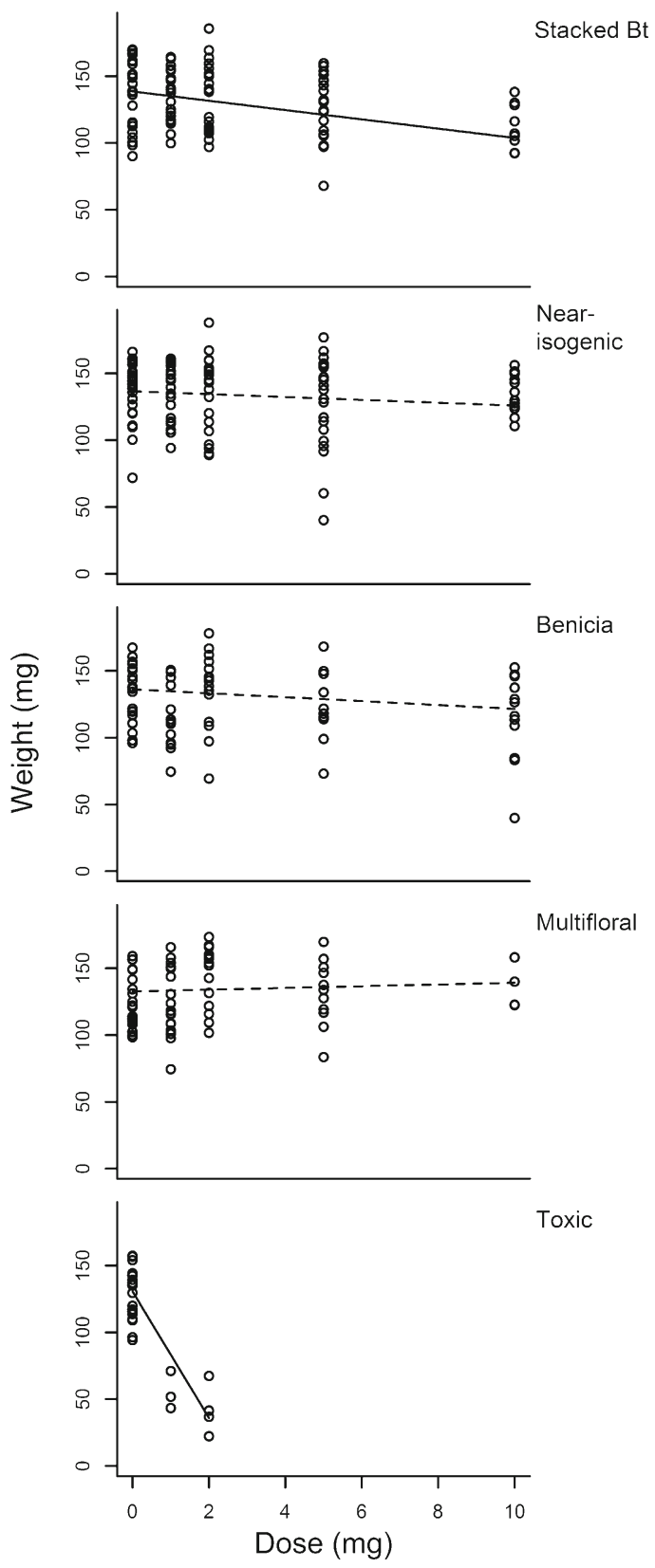

Figure 3. This graph shows the prepupal weight in response to pollen type and dosage (amount of pollen fed in larval phase). Each graph shows the dose-response regression line for a specific pollen type, dashed lines show non-significant relationships, solid lines show a significant decrease with increasing dose. Statistics are reported in Table II. 
Table II. This table shows the effects of different pollen treatments on prepupal weight.

\begin{tabular}{lrrrrl}
\hline Hypotheses & Estimate & Std. error & $z$ value & $p$ value & Significance \\
\hline slopeMF-0 =0 & 0.6530 & 0.9750 & 0.670 & 0.50302 & \\
slopeBt-0 =0 & -3.4911 & 0.7064 & -4.942 & $2.32 \mathrm{e}-06$ & $* * *$ \\
slopeC-0=0 & -1.0686 & 0.6147 & -1.739 & 0.0924 & \\
slopeBen-0=0 & -1.4735 & 0.7309 & -2.016 & 0.0563 & \\
slopeTox-0=0 & -47.3815 & 5.0938 & -9.302 & $<2 \mathrm{e}-16$ & $* * *$ \\
slopeBt-slopeMF=0 & -4.1440 & 1.0988 & -3.771 & 0.0004 & $* * *$ \\
slopeBt-slopeC=0 & -2.4224 & 0.8616 & -2.811 & 0.0089 & $* *$ \\
slopeBt-slopeBen=0 & -2.0176 & 0.9213 & -2.190 & 0.0428 & $*$ \\
slopeBt-slopeTox=0 & 43.8904 & 5.1161 & 8.579 & $<2 \mathrm{e}-16$ & $* * *$ \\
\hline
\end{tabular}

The first part of the table shows whether there is a dose-dependent effect of feeding an increased amount of pollen and the second part shows whether the stacked Bt treatment differs from the control treatments, where slope is the effect of increasing amounts pollen fed, on the measured weight. Slopes are compared against zero, i.e., compared to no effect of increasing amount of pollen fed, and the slope of the stacked Bt treatment is compared to the slope of all controls

$M F=$ multifloral, $B t=$ stacked $\mathrm{Bt}, C=$ comparator, or the near isogenic to the stacked $\mathrm{Bt}, \mathrm{Ben}=$ Benicia; another conventionally grown maize cultivar, Tox =toxic pollen from Heliconia jacquinii

Asterisks depict level of significance: ${ }^{*} p<0.05,{ }^{* *} p<0.01,{ }^{* * *} p<0.001$

assessment endpoints survival and prepupal weight, two new assessment endpoints, pollen digestibility and developmental delay, were included in the in vitro larvae rearing test system. The pollen of the insect resistant $\mathrm{Bt}$ maize did not show significant dose-dependent effects on survival rates, pollen digestion, and developmental delay, whereas weight did show a significant negative dose-dependent response.

\subsection{Digestion}

Our data clearly show that honey bee larvae are able to digest the administered pollen, and as such

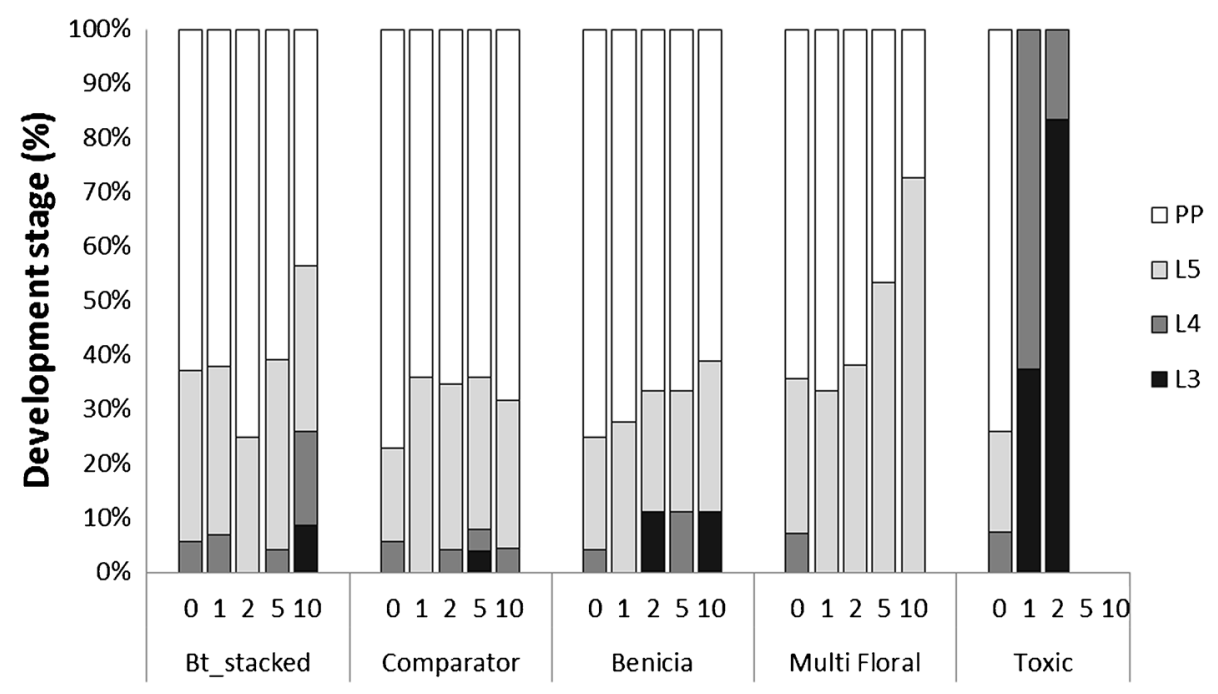

Figure 4. Development stages of larvae at the end of the experiment, at D11. The $x$ axis depicts the pollen type, and the amount of pollen (in milligram) fed to the larvae. $Y$ axis shows what percentage belongs to which development stage; $P P$ stands for prepupa, $L 5$ for fifth instar larva, $L 4$ for fourth instar larva, and $L 3$ for third instar larva. Statistical values are reported in text. 
become exposed to potentially toxic proteins therein. We found that, irrespective of the amount of pollen being fed, the maize pollen was better digested than multifloral pollen. Bt pollen was digested equally well as the other two maize pollen treatments. This is highly relevant, because the larval stage is theoretically the most Cry proteinsensitive stage during bee development (Glare and O'Callaghan 2000; Schmidt et al. 2009; Romeis et al. 2011). An absence of a detrimental effect of $\mathrm{Bt}$ pollen on gut functioning was recently also shown for adult nurse bees under semi-field conditions (Hendriksma et al. 2013). The microbiota in the gut of larvae and adult bees are not affected by ingestion of Bt pollen (Geng et al. 2013; Hendriksma et al. 2013).

In our in vitro study, the observed degree of digestion of pollen grains was rather low in comparison to other studies. Babendreier et al (2004) found under semi-field conditions in the gut of bee larvae that on average $74.5 \%$ of the maize pollen grains were fully digested, which is very high compared to $6.7 \%$ in our study. Hendriksma et al (2013) detected an overall average weighted digestion rate of $62.7 \%$ maize pollen in adult honey bees, which is in line with what Schmidt and Buchmann (1985) described for the digestibility of a mixture of pollen of $77 \%$. Our results however are remarkably lower with an average weighted digestibility of $19.5 \%$. This could indicate that the pollen digestion capacity of honey bee larvae is limited when facing pollen amounts of up to $10 \mathrm{mg}$ pollen. In contrast to field and semifield data, our utilized pollen was hand collected (maize treatments) or caught in a pollen trap before in hive processing (multifloral pollen treatment). As a consequence, the pollen never came into contact with nurse bees, nor did it go through the stage of being stored as beebread inside the hive. Storing beebread most probably has the function of preservation and not pre-digestion (Anderson et al. 2014). However, the effects of the microbial community in beebread on the (transgenic) proteins therein are still largely unknown; hence, the true exposure of bee larvae to Cry proteins in the field is also unknown. The microbial community in the guts of honey bee larvae is known to differ from that of adult honey bees (Mohr and Tebbe 2006; Martinson et al. 2012), and it changes over time (Vojvodic et al. 2013). The exact mechanisms driving the development of gut microbiota in honey bee larvae is not yet identified (Martinson et al. 2012). The lack of contact with nurse bees could be the reason why our in vitroreared larvae could not digest the pollen as well compared to the semi-field situation (Babendreier et al. 2004). A further implication of the lower degree of pollen digestion is that the exposure to $\mathrm{Bt}$ proteins also is downscaled in studies where hand-collected Bt pollen is fed. Based on the pollen digestibility in our study, the in vitro-reared larvae are only exposed to $35 \%$ of the pollen protein content compared to bee-processed maize pollen (data from Babendreier et al. 2004). Thus, there is a big potential to underestimate possible Bt effects on bee larvae when using hand-collected pollen in an in vitro-rearing assay.

\subsection{Survival}

Larvae that received toxic pollen show a four times higher mortality rate than larvae that received multifloral pollen. The toxic effect became stronger at higher doses of toxic pollen, showing that dose-dependent effects are detectable in our bioassay. This highlights the general relevance of our test method for ERAs. Our data indicate that even at high doses, Bt maize pollen does not have a negative effect on the survival of honey bee larvae. Our finding is in accordance with other studies that show no impact of transgenic $\mathrm{Bt}$ maize pollen (Hanley et al. 2003) on larval/ prepupal survival. Mortality of adult nurse bees is not adversely affected by stacked Bt maize pollen (Hendriksma et al. 2013) or Bt cotton pollen (Liu et al. 2005, 2009; Niu et al. 2013). A meta-analysis that encompassed 25 datasets also found no negative effects of transgenic Bt plant products on honey bees (Duan et al. 2008). The few studies that investigate direct effects of transgenic pollen on honey bee larvae also did not find negative effects on survival rates (Huang et al. 2004; Hendriksma et al. 2011b).

\subsection{Prepupal weight}

We did detect a dose-dependent negative effect of $\mathrm{Bt}$ maize pollen on prepupal weight in our in vitro test assay. Nevertheless, under semi-field conditions, developing brood exclusively exposed to flowering 
Bt maize of the same variety as in our study did not show a significant effect on hatching weight (Härtel et al., unpublished data) and similarly nurse bees did not show a reduction in body weight when exposed to purified stacked Bt proteins (Hendriksma et al. 2013). In an in vitro-rearing study that tested only a single amount of transgenic pollen ( $2 \mathrm{mg}$; Hendriksma et al. 2011b), no negative effect of transgenic pollen on prepupal weight was detected. Hendriksma et al. (2012) could also show that the exposure to the same purified Bt proteins, at 186 times the estimated environmental concentration (EEC), did not affect the prepupal weight of in vitro-reared larvae. This underlines the importance of directly using the transgenic plant material and testing it in a dose-depending manor. However, since hatching weight did not show any effect when bees were reared exclusively on Bt maize pollen, our highest doses fed (5 and $10 \mathrm{mg}$ ) probably depict worst case scenarios that are not likely to occur under field conditions. The observed sub-lethal effect on prepupal weight is most likely not related to the Bt protein itself, but rather a pleiotropic effect. The transgenic constructs in the genome of the stacked Bt maize plant might have altered the nutritional value of the pollen grain. For example, in three different transgenic maize varieties (with the events 176, Bt11, and MON810), lignin contents were demonstrably higher than in their nearisogenic comparators (Saxena and Stotzky 2001; Flores et al. 2005), and in potato, three different transgenes (GNA, Con A, CpTi) also reduced glycoalkaloid content (Birch et al. 2002). A recent study showed that stacking transgenes can reduce expression of other proteins when comparing them to the parental lines or with the isogenic line; out of 22 quantified proteins nine, other than the transgenic proteins, had lower expression levels (AgapitoTenfen et al. 2014) which could explain our observed effect on prepupal weight. We found a sublethal weight reduction of $3.5 \mathrm{mg}$ per $1 \mathrm{mg}$ Bt pollen fed. In comparison to the positive control, this effect was more than tenfold smaller. It has to be mentioned that in our study, the other maize pollen treatments, the near isogenic pollen and the conventional pollen, also show a marginal negative dosedependent effect on the prepupal weight (Table II), but only for the Bt treatment group did we find a significant result. We would like to point out that additional experiments on the actual exposure of honey bees to Cry proteins and possible nutritional alterations in Bt pollen are needed.

\subsection{Developmental delay}

Overall, our larvae developed slower than they would in the hive. None of the larvae had reached the pupal stage at the end of the experiment at D11. It is known that in vitro-reared larvae reach their maximal weight 1 day later than in larvae reared in the hive, and larvae stretch 1-3 days later compared to the in hive situation (Riessberger-Gallé et al. in Scheiner et al. 2008). We found a dosedependent effect of delayed development in our positive control group, the toxic pollen. This shows the informative value of developmental delay as a new quantifiable, sub-lethal assessment endpoint in ERA's. Our findings were in accordance with a study where a purified Bt protein was fed where honey bee larvae did not have a delayed development compared to the control (Lima et al. 2010).

\section{CONCLUSION}

By directly feeding pollen, we have mimicked the natural exposure route of honey bee larvae to GM proteins. We assume that exposition rates could be even higher for larvae fed with preprocessed pollen in real colonies. We further have demonstrated that dose-dependent effects are detectable with this experimental approach. Honey bee larvae had reduced prepupae weight at increasing amounts of Bt pollen. This illustrates the importance of incorporating a range of test doses when testing GM plant material in an ERA. Further studies are required to evaluate the underlying mechanism of this negative effect and its relevance for colony fitness in the field. Future in vitro larvae-rearing studies testing the effects of GM pollen (or pollen contaminated with systemic insecticides) should incorporate pollen digestibility as assessment endpoint. Our data suggest that general efforts must be made to quantify how many Bt protein effectively reach honey bee larvae, which are theoretically the most Bt-sensitive life stage of honey bee colonies. Experiments analyzing the $\mathrm{Bt}$ protein content in stored beebread as well as in Bt pollen administered as larval food are needed 
to integrate the results of laboratory studies and to adapt the experimental design for new ERA's.

\section{ACKNOWLEDGMENTS}

This is the publication no. 9 produced within the framework of the project Assessing and Monitoring the Impacts of Genetically Modified Plants on Agro-ecosystems (AMIGA), funded by the European Commission in the Framework programme 7, THEME [KBBE.2011.3.5-01]. We would like to thank Harmen Hendriksma for mentoring during the begin stages of this experiment, Ulrike Rießberger-Gallé for very useful tips regarding in vitro rearing of honey bees, and Katharina Beer and Theresa Hügel for their assistance in the lab. Many thanks go out to Bernhard Hoiß, Emily Martin, Marcel Peters, and Sabine Karl for advice regarding the statistical analysis. And special thanks to Nadja Danner and Milica Laković for proofreading the manuscript.

Tests 'dose-dependants ' portant sur les effets du maïs de pollen Bt issu de l'empilement génétique sur des larves d 'abeilles élevées in vitro

\section{Évaluation du risque environnemental / pollen transgénique / Apis mellifera / écotoxicologie / effets sublétaux}

\section{Testen von dosisabhängigen Effekten von Bt Maispollen} auf in vitro aufgezogenen Honigbienenlarven

Umweltrisikoabschätzung / transgener Pollen / Apis mellifera / Ökotoxikologie / subletale Effekte

\section{REFERENCES}

Agapito-Tenfen, S.Z., Vilperte, V., Benevenuto, R.F., Rover, C.M., Traavik, T.I., et al. (2014) Effect of stacking insecticidal cry and herbicide tolerance epsps transgenes on transgenic maize proteome. BMC Plant Biol. 14, 346

Anderson, K.E., Carroll, M.J., Sheehan, T., Mott, B.M., Maes, P., et al. (2014) Hive-stored pollen of honey bees: many lines of evidence are consistent with pollen preservation, not nutrient conversion. Mol. Ecol. 23 (23), 5904-5917

Andow, D.A., Hilbeck, A. (2004) Science-based risk assessment for nontarget effects of transgenic crops. Bioscience 54 (7), 637-649

Aupinel, P., Fortini, D., Dufour, H., Tasei, J.-N., Michaud, B., et al. (2005) Improvement of artificial feeding in a standard in vitro method for rearing Apis mellifera larvae. Bull. Insectol. 58(2), 107-111
Aupinel P., D. Fortini, B. Michaud, P. Medrzycki, E. Padovani, et al. (2009) Honey bee brood ring-test: method for testing pesticide toxicity on honeybee brood in laboratory conditions, Julius-Kühn-Archiv, 96-102.

Babendreier, D., Kalberer, N., Romeis, J., Fluri, P., Bigler, F. (2004) Pollen consumption in honey bee larvae: a step forward in the risk assessment of transgenic plants. Apidologie 35 (3), 293-300

Babendreier, D., Kalberer, N.M., Romeis, J., Fluri, P., Mulligan, E., et al. (2005) Influence of Bt-transgenic pollen, Bt-toxin and protease inhibitor (SBTI) ingestion on development of the hypopharyngeal glands in honeybees. Apidologie 36 (4), 585-594

Bates D., M. Maechler, B. Bolker, S. Walker (2013) lme4: Linear mixed-effects models using Eigen and S4., in: R package version 1.0-5. http://CRAN.R-project.org/ package=lme4 R.p.v.-. (Ed.).

Benjamini, Y., Yekutieli, D. (2001) The control of the false discovery rate in multiple testing under dependency. Ann. Stat. 29(4), 1165-1188

Birch, A.N.E., Geoghegan, I.E., Griffiths, D.W., McNicol, J.W. (2002) The effect of genetic transformations for pest resistance on foliar solanidine-based glycoalkaloids in potato (Solanum tuberosum). Assoc. Appl. Biol. 140, 143-149

Christensen R.H.B. (2013) Ordinal-regression models for ordinal data $\mathrm{r}$ package, version 2013.9-30 http:// www.cran.r-project.org/package $=$ ordinal/.

Crailsheim, K. (1990) The protein balance of the honey bee worker. Apidologie 21, 417-429

Crailsheim, K., Schneider, L.H.W., Hrassnigg, N., Bühlmann, G., Brosch, U., et al. (1992) Pollen consumption and utilization in worker honeybees (Apis mellifera carnica): dependence on individual age and function. J. Insect Physiol. 38(6), 409-419

Danner, N., Härtel, S., Steffan-Dewenter, I. (2014) Maize pollen foraging by honey bees in relation to crop area and landscape context. Basic Appl. Ecol. 15(8), 677-684

Duan, J.J., Lundgren, J.G., Naranjo, S., Marvier, M. (2010) Extrapolating non-target risk of Bt crops from laboratory to field. Biol. Lett. 6(1), 74-77

Duan, J.J., Marvier, M., Huesing, J., Dively, G., Huang, Z.Y. (2008) A meta-analysis of effects of Bt crops on honey bees (Hymenoptera: apidae). Plos One 3 (1), e1415. doi:10.1371/journal.pone.0001415

Flores, S., Saxena, D., Stotzky, G. (2005) Transgenic Bt plants decompose less in soil than non-Bt plants. Soil Biol. Biochem. 37, 1073-1082

Geng, L.-L., Cui, H.-J., Dai, P.-L., Lang, Z.-H., Shu, C.-L., et al. (2013) The influence of Bt-transgenic maize pollen on the bacterial diversity in the midgut of Apis mellifera ligustica. Apidologie 44 (2), 198-208

Glare, T.R., O’Callaghan, M. (2000) Bacillus thuringiensis : biology, ecology and safety. Wiley, Chichester

Hanley, A.V., Huang, Z.Y., Pett, W.L. (2003) Effects of dietary transgenic Bt corn pollen on larvae of Apis mellifera and Galleria mellonella. J. Apic. Res. 42 (4), 77-81 
Haydak, M.H. (1943) Larval food and development of castes in the honeybee. J. Econ. Entomol. 36, 778-792

Hendriksma, H.P., Härtel, S., Babendreier, D., Ohe, W.V.D., Steffan-Dewenter, I. (2012) Effects of multiple Bt proteins and GNA lectin on in vitro-reared honey bee larvae. Apidologie 43 (5), 549-560

Hendriksma, H.P., Härtel, S., Steffan-Dewenter, I. (2011a) Honey bee risk assessment: new approaches for in vitro larvae rearing and data analyses. Meth. Ecol. Evol. 2 (5), 509-517

Hendriksma, H.P., Härtel, S., Steffan-Dewenter, I. (2011b) Testing pollen of single and stacked insect-resistant Bt-maize on in vitro reared honey bee larvae. Plos One 6(12), 28174. doi:10.1371/ journal.pone.0028174

Hendriksma, H.P., Küting, M., Härtel, S., Näther, A., Dohrmann, A.B., et al. (2013) Effect of stacked insecticidal cry proteins from maize pollen on nurse bees (Apis mellifera carnica) and their gut bacteria. Plos One 8(3), e59589. doi:10.1371/journal.pone.0059589

Hothorn, T., Bretz, F., Westfall, P. (2008) Simultaneous inference in general parametric models. Biom. J. 50(3), 346-363

Hrassnigg, N., Crailsheim, K. (2005) Differences in drone and worker physiology in honeybees (Apis mellifera). Apidologie 36(2), 255-277

Huang, Z.Y., Hanley, A.V., Pett, W.L., Langenberger, M., Duan, J.J. (2004) Field and semifield evaluation of impacts of transgenic canola pollen on survival and development of worker honey bees. J. Econ. Entomol. 97 (5), 1517-1523

James C. (2013) Global Status of Commercialized Biotech/ GM Crops: 2013., in: ISAAA (Ed.), ISAAA Brief No. 46., Ithaca

Keller, I., Fluri, P., Imdorf, A. (2005) Pollen nutrition and colony development in honey bees: part I. Bee World 86 (1), 3-10

Lima, M.A.P., Pires, C.S.S., Guedes, R.N.C., Nakasu, E.Y.T., Lara, M.S., et al. (2010) Does Cry1Ac Bttoxin impair development of worker larvae of Africanized honey bee? J. Appl. Entomol. doi:10.1111/j.14390418.2010.01573.x

Liu, B., Shu, C., Xue, K., Zhou, K., Li, X., et al. (2009) The oral toxicity of the transgenic $\mathrm{Bt}+\mathrm{CpTI}$ cotton pollen to honeybees (Apis mellifera). Ecotoxicol. Environ. Saf. 72 (4), 1163-1169

Liu, B., Xu, C.G., Yan, F.M., Gong, R.Z. (2005) The impacts of the pollen of insect-resistant transgenic cotton on honeybees. Biodivers. Conserv. 14(14), 3487-3496

Malone, L.A., Tregidga, E.L., Todd, J.H., Burgess, E.P.J., Philip, B.A., et al. (2002) Effects of ingestion of a biotin-binding protein on adult and larval honey bees. Apidologie 33 (5), 447-458

Martinson, V.G., Moy, J., Moran, N.A. (2012) Establishment of characteristic gut bacteria during development of the honeybee worker. Appl. Environ. Microbiol. 78(8), 2830. doi:10.1128/AEM.07810-11

Mohr, K.I., Tebbe, C.C. (2006) Diversity and phylotype consistency of bacteria in the guts of three bee species (Apoidea) at an oilseed rape field. Environ. Microbiol. $\mathbf{8}(2), 258-272$

Niu, L., Ma, Y., Mannakkara, A., Zhao, Y., Ma, W., et al. (2013) Impact of single and stacked insect-resistant Btcotton on the honey bee and silkworm. Plos One 8(9), e72988. doi:10.1371/journal.pone.0072988

RCoreTeam (2013) R: A language and environment for statistical computing. R Foundation for Statistical Computing, Vienna, Austria. http://www.Rproject.org/.

Romeis, J., Hellmich, R.L., Candolfi, M.P., Carstens, K., De Schrijver, A., et al. (2011) Recommendations for the design of laboratory studies on non-target arthropods for risk assessment of genetically engineered plants. Transgenic Res. 20 (1), 1-22

Saxena, D., Stotzky, G. (2001) Bt corn has a higher lignin content than non-Bt corn. Am. J. Bot. 88(9), 1704-1706

Scheiner, R., Alkattea, R., Steidle, H., Rosenkranz, P., Grünewald, B., et al. (2008) Association of Institutes for Bee Research report of the 55th seminar in Hohen Neuendorf 11-13March 2008. Apidologie 39(5), 588604

Schmidt, J.E.U., Braun, C.U., Whitehouse, L.P., Hilbeck, A. (2009) Effects of activated Bt transgene products (Cry1Ab, Cry3Bb) on immature stages of the ladybird Adalia bipunctata in laboratory ecotoxicity testing. Arch. Environ. Contam. Toxicol. 56(2), 221-228

Schmidt, J.O., Buchmann, S.L. (1985) Pollen digestion and nitrogen utilization by Apis mellifera L. (Hymenoptera: Apidae). Comp. Biochem. Physiol. A Physiol. 82 (3), 499-503

Schnepf, E., Crickmore, N., Van Rie, J., Lereclus, D., Baum, J., et al. (1998) Bacillus thuringiensis and its pesticidal crystal proteins. Microbiol. Mol. Biol. Rev. $62(3), 775-806$

Schuppener, M., Muehlhause, J., Mueller, A.-K., Rauschen, S. (2012) Environmental risk assessment for the small tortoiseshell Aglais urticae and a stacked Bt-maize with combined resistances against Lepidoptera and Chrysomelidae in central European agrarian landscapes. Mol. Ecol. 21 (18), 4646-4662

Therneau T. (2012) coxme: mixed effects Cox models. R package version 2.2-3. http://CRAN.R-project.org/ package $=$ coxme.

Vojvodic, S., Rehan, S.M., Anderson, K.E. (2013) Microbial gut diversity of Africanized and European honey bee larval instars. PLoS One 8(8), e72106

Whitehouse, M.E.A., Wilson, L.J., Davies, A.P., Cross, D., Goldsmith, P., et al. (2014) Target and nontarget effects of novel "triple-stacked" Bt-transgenic cotton 1: canopy arthropod communities. Environ. Entomol. 43 (1), 218-241 